\title{
MODULATION OF ANABOLIC AND CATABOLIC RESPONSES VIA A POROUS POLYMER SCAFFOLD MANUFACTURED USING THERMALLY INDUCED PHASE SEPARATION
}

Nicole Y.C Yu ${ }^{1,2, *}$, Aaron Schindeler ${ }^{1,3, *}$, Lauren Peacock ${ }^{1}$, Kathy Mikulec ${ }^{1}$, Jane Fitzpatrick ${ }^{4}$, Andrew J. Ruys ${ }^{2}$, Justin J. Cooper-White ${ }^{4}$ and David G. Little ${ }^{1,3}$

\begin{abstract}
${ }^{1}$ Department of Orthopaedic Research \& Biotechnology, The Children's Hospital at Westmead, Locked Bag 4001, Westmead, NSW, 2145, Australia

${ }^{2}$ School of Aerospace, Mechanical and Mechatronic Engineering, J07 University of Sydney, NSW, 2006, Australia ${ }^{3}$ Discipline of Paediatrics and Child Health, Faculty of Medicine, A27 University of Sydney, NSW, 2006, Australia ${ }^{4}$ Tissue Engineering and Microfluidics Laboratory, Australian Institute for Nanotechnology and Bioengineering and the School of Chemical Engineering, University of Queensland, Brisbane, QLD, Australia
\end{abstract}

\begin{abstract}
We describe two studies encompassing the iterative refinement of a polymer-based rhBMP-2 delivery system for bone tissue engineering. Firstly, we compared the boneforming capacity of porous poly(D,L-lactic-co-glycolic acid) (PLGA) scaffolds produced by thermally induced phase separation (TIPS) with non-porous solvent cast poly(D,L-lactic acid) (PDLLA) used previously. Secondly, we examined the potential synergy between rhBMP-2 and local bisphosphonate in the PLGA scaffold system.

In vivo ectopic bone formation studies were performed in C57BL6/J mice. Polymer scaffolds containing 0, 5, 10 or $20 \mu \mathrm{g}$ rhBMP-2 were inserted into the dorsal musculature. At all rhBMP-2 doses, porous PLGA produced significantly higher bone volume $\left(\mathrm{BV}, \mathrm{mm}^{3}\right)$ than the solid PDLLA scaffolds. Next, porous PLGA scaffolds containing $10 \mu \mathrm{g}$ rhBMP- $2 \pm 0.2$, or $2 \mu \mathrm{g}$ zoledronic acid (ZA) were inserted into the hind-limb musculature. Co-delivery of local $10 \mu \mathrm{g}$ rhBMP-2/2 $\mu \mathrm{g}$ ZA significantly augmented bone formation compared with rhBMP-2 alone (400\% BV increase, $p<0.01$ ). Hydroxyapatite microparticle (HAp) addition $(2 \% \mathrm{w} / \mathrm{w})$ to the $10 \mu \mathrm{g}$ rhBMP-2/0.2 $\mu \mathrm{g}$ ZA group increased BV $(200 \%, p<0.01)$. We propose that this was due to controlled ZA release of HAp-bound ZA. Consistent with this, elution analyses showed that HAp addition did not alter the rhBMP-2 elution, but delayed ZA release. Moreover, $2 \% \mathrm{w} / \mathrm{w}$ HAp addition reduced the scaffold's compressive properties, but did not alter ease of surgical handling.

In summary, our data show that refinement of the polymer selection and scaffold fabrication can enhance rhBMP-2 induced bone formation in our bone tissue engineering implant, and this can be further optimised by the local co-delivery of ZA/HAp.
\end{abstract}

Keywords: Zoledronic acid; bisphosphonate; rhBMP-2; bone morphogenetic protein; bone tissue engineering; biodegradable polymer scaffold; thermally induced phase separation.

*Address for correspondence:

N.Y.C Yu or A. Schindeler

Orthopaedic Research \& Biotechnology

Research Building

The Children's Hospital at Westmead

Locked Bag 4001

Westmead, NSW 2145, Australia
Telephone Number: +61-2-98451451

FAX Number: +61-2-98453078

E-mail: nicole.yu@sydney.edu.au, aaron.schindeler@sydney.edu.au

\section{Introduction}

The Diamond Concept of bone tissue engineering proposes that a tissue engineering outcome is dependent on the selection of growth factors, type of scaffold or matrix, population(s) of osteogenic cells, and the amount of mechanical loading (Giannoudis et al., 2007). Recombinant human bone morphogenetic proteins (rhBMPs) such as rhBMP-2 and rhBMP-7/OP-1 can potently stimulate new bone formation and are clinically used in the treatment of spinal fusion, delayed and nonunions, and critical sized bone defects. Purified collagen is the primary delivery system in clinical use. However, cost and prion-disease risk have led many groups to examine alternative delivery systems. As previously reviewed by our group, biodegradable polymers are emerging as promising synthetic biomaterials for the controlled release of osteogenic growth factors (Yu et al., 2010a). Furthermore, synthetic materials avoid potential immunogenic response or disease transfer associated with collagen materials (DeLustro et al., 1990; Geesink et al., 1999; Olsen et al., 2003; Kato et al., 2006).

Bone resorption can be particularly problematic in situations where rhBMPs are used. High BMP local concentrations can increase osteoclast activity (Kaneko et al., 2000; Itoh et al., 2001) and cause premature bone resorption (Pradhan et al., 2006). In addition, many tissueengineering implants are unloaded or subjected to stress shielding, which can also increase resorptive pressures (Wolff, 1892). In a model described by us in 2005, we proposed that optimal orthopaedic repair requires an appropriate balance between anabolism (bone formation) and catabolism (bone resorption) (Little et al., 2005; Little et al., 2007). In the context of bone tissue engineering the use of anti-resorptive agents may compensate for bone loss due to poor mechanics and potentially maximise bone outcomes (Yu et al., 2012 ).

A number of preclinical studies have shown synergy between rhBMPs and bisphosphonates. Systemic bisphosphonate dosing given immediately post-operatively or 2 weeks post-operatively increased rhBMP-7/OP-1 
Table 1. Surgical experimental groups.

\begin{tabular}{|c|c|c|c|c|c|c|}
\hline Group & Surgical model & Polymer scaffold & Local anabolic agent & Anti-catabolic agent & Animals & Exclusions \\
\hline 1 & $\begin{array}{l}\text { Dorsal muscle } \\
\text { pouch }\end{array}$ & Solid PDLLA & $\begin{array}{c}\text { rhBMP-2 } \\
(0,5,10,20 \mu \mathrm{g})\end{array}$ & $0 \mu \mathrm{g} Z A$ & $6^{*}$ & $\begin{array}{c}0(0 \mu \mathrm{g} \text { rhBMP- }) \\
0(5 \mu \mathrm{g} \text { rhBMP-2) } \\
1(10 \mu \mathrm{g} \text { rhBMP- } 2) \\
0(20 \mu \mathrm{g} \text { rhBMP- } 2)\end{array}$ \\
\hline 2 & $\begin{array}{l}\text { Dorsal muscle } \\
\text { pouch }\end{array}$ & $\begin{array}{c}\text { Porous PLGA } \\
\text { (quick quench, TIPS) }\end{array}$ & $\begin{array}{c}\text { rhBMP-2 } \\
(0,5,10,20 \mu \mathrm{g})\end{array}$ & $0 \mu \mathrm{g} \mathrm{ZA}$ & $6^{*}$ & $\begin{array}{l}0(0 \mu \mathrm{g} \text { rhBMP-2 }) \\
1(5 \mu \mathrm{g} \mathrm{rhBMP}-2) \\
0(10 \mu \mathrm{g} \text { rhBMP-2) } \\
0(20 \mu \mathrm{g} \text { rhBMP-2 })\end{array}$ \\
\hline 3 & $\begin{array}{l}\text { Dorsal muscle } \\
\text { pouch }\end{array}$ & $\begin{array}{c}\text { Porous PLGA } \\
\text { (slow quench, TIPS) }\end{array}$ & $\begin{array}{c}\text { rhBMP-2 } \\
(0,5,10,20 \mu \mathrm{g})\end{array}$ & $0 \mu \mathrm{g} \mathrm{ZA}$ & $6^{*}$ & $\begin{array}{c}0(0 \mu \mathrm{g} \text { rhBMP-2) } \\
0(5 \mu \mathrm{g} \mathrm{rhBMP}-2) \\
1(10 \mu \mathrm{g} \text { rhBMP-2) } \\
0(20 \mu \mathrm{g} \text { rhBMP-2 })\end{array}$ \\
\hline 4 & $\begin{array}{l}\text { Hind-limb muscle } \\
\text { pouch }\end{array}$ & $\begin{array}{c}\text { Porous PLGA } \\
\text { (slow quench, TIPS) }\end{array}$ & $10 \mu \mathrm{g}$ rhBMP-2 & $0 \mu \mathrm{g} Z \mathrm{~A}$ & 8 & 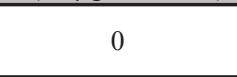 \\
\hline 5 & $\begin{array}{l}\text { Hind-limb muscle } \\
\text { pouch }\end{array}$ & $\begin{array}{c}\text { Porous PLGA } \\
\text { (slow quench, TIPS) } \\
\end{array}$ & $10 \mu \mathrm{g}$ rhBMP-2 & Local $0.2 \mu \mathrm{g} \mathrm{ZA}$ & 8 & 0 \\
\hline 6 & $\begin{array}{l}\text { Hind-limb muscle } \\
\text { pouch }\end{array}$ & $\begin{array}{c}\text { Porous PLGA } \\
\text { (slow quench, TIPS) }\end{array}$ & $10 \mu \mathrm{g}$ rhBMP-2 & Local $2 \mu \mathrm{g}$ ZA & 8 & 2 \\
\hline 7 & $\begin{array}{l}\text { Hind-limb muscle } \\
\text { pouch }\end{array}$ & $\begin{array}{l}\text { HAp/Porous PLGA } \\
\text { (slow quench, TIPS) }\end{array}$ & $10 \mu \mathrm{g}$ rhBMP-2 & $\begin{array}{c}\text { Local } 0.2 \mu \mathrm{g} \mathrm{ZA} \\
\text { (via } 2 \% \mathrm{HAp})\end{array}$ & 8 & 1 \\
\hline 8 & $\begin{array}{l}\text { Hind-limb muscle } \\
\text { pouch }\end{array}$ & $\begin{array}{c}\text { Porous PLGA } \\
\text { (slow quench, TIPS) }\end{array}$ & $10 \mu \mathrm{g}$ rhBMP-2 & $\begin{array}{c}\text { Systemic } 0.1 \mathrm{mg} / \mathrm{kg} \\
(2 \mu \mathrm{g} \text { ZA total })\end{array}$ & 8 & 2 \\
\hline
\end{tabular}

* Each animal was implanted with same scaffold type with 4 different rhBMP-2 doses.

induced bone formation in a rat critical-sized defect model (Little et al., 2005). This led to increased union rates and mechanical strength at 6 weeks. Other studies have illustrated advantages of this systemic bisphosphonates dosing in a rat ectopic bone formation model (Gong et al., 2003), an unloaded rat bone chamber model (Tägil et al., 2006; Harding et al., 2008), and non-human primate models (Bouxsein et al., 2001; Seeherman et al., 2001).

For bisphosphonates, local delivery has emerged as an appealing alternative to systemic delivery for two reasons. Firstly, local dosing can lower the absolute bisphosphonate dose required. Secondly, systemic bisphosphonates are associated with adverse events including stomach ulceration (oral bisphosphonates) and flu-like symptoms (intravenous dosing) (Thiébaud et al., 1997; Mönkkönen et al., 1998), and in rare cases renal failure and osteonecrosis of the jaw (Marx, 2005). A number of studies have shown positive effects by delivering both rhBMPs and bisphosphonates locally (Jeppsson et al., 2003; Chen et al., 2004; Chen et al., 2006; Belfrage et al., 2011).

Our group has previously examined the effects of combining rhBMP-7 with local bisphosphonate $(0.02 \mathrm{mg}$, $0.2 \mathrm{mg}$, and $2 \mathrm{mg}$ pamidronate) in solvent cast poly(D,Llactic acid) (PDLLA) discs (Yu et al., 2010b). After 3 weeks, local low dose pamidronate $(0.02 \mathrm{mg})$ was found to augment rhBMP-2 induced bone formation to a similar capacity to systemic co-treatment $(0.3$ and $3.0 \mathrm{mg} / \mathrm{kg}$, thrice weekly). Notably, local high dose pamidronate $(2 \mathrm{mg})$ adversely affected bone formation, highlighting potential negative effects that have been previously associated with high local concentrations of bisphosphonate (Choi et al., 2007; Jakobsen et al., 2007; Jakobsen et al., 2010). Consequently, we further speculated that the addition of a calcium phosphate based biomaterial, which could sequester and/or delay local bisphosphonate release, may further improve bone formation outcomes. In addition, bound bisphosphonate may be preferentially phagocytosed by osteoclasts (Coathup et al., 2001).

This report details a systematic process for developing an alternative synthetic biodegradable delivery system for rhBMP-2 delivery. This involved a two-step process for validating the biomaterial selection and fabrication process using a range of rhBMP-2 doses, and for the introduction of zoledronic acid (ZA) and hydroxyapatite microparticles (HAp). The thermally induced phase separation (TIPS) manufactured PLGA polymer was selected based on its faster degradation rate, as PDLLA discs showed poor biodegradation in a prior study with 3 and 8 week endpoints (Yu et al., 2010b). This study shows, for the first time, the potential of rhBMP-2 delivery by a TIPS manufactured scaffold, which combines modulation by locally delivered anti-resorptive drugs.

\section{Materials and Methods}

\section{Experimental design}

In the first animal study, porous PLGA scaffolds and solvent cast PDLLA discs were compared as rhBMP-2 delivery systems in a mouse dorsal muscle pouch model. A range of rhBMP-2 doses were examined (Table 1). In the second animal study, the dose of $10 \mu \mathrm{g}$ rhBMP-2 in porous PLGA scaffolds was selected for further refinement. Scaffolds were tested with and without $0.2 \mu \mathrm{g} \mathrm{ZA,} 2 \mu \mathrm{g}$ $\mathrm{ZA}$, and $0.2 \mu \mathrm{g}$ ZA with $2 \% \mathrm{w} / \mathrm{w}$ HAp microparticles in a hind-limb muscle pouch model. A systemic ZA dosing group was also included (Table 1). For all in vivo models, the end point was 3 weeks.

To investigate the PGLA scaffolds mechanistically, scanning electron microscopy, compression testing, and 
Table 2. Mechanical testing polymer scaffold groups.

\begin{tabular}{cccc}
\hline Group & Polymer scaffold & Hap \% w/w (of PLGA) & $\boldsymbol{n}$ \\
\hline $\mathbf{1}$ & $\begin{array}{c}\text { Porous PLGA } \\
\text { (slow quench, SQ TIPS) }\end{array}$ & $0 \%$ & 5 \\
\hline $\mathbf{2}$ & $\begin{array}{c}\text { HAp/Porous PLGA } \\
\text { (slow quench, SQ TIPS) }\end{array}$ & $1 \%$ & 7 \\
\hline $\mathbf{3}$ & $\begin{array}{c}\text { HAp/Porous PLGA } \\
\text { (slow quench, SQ TIPS) }\end{array}$ & $2 \%$ & 7 \\
\hline $\mathbf{4}$ & $\begin{array}{c}\text { HAp/Porous PLGA } \\
\text { (slow quench, SQ TIPS) }\end{array}$ & $5 \%$ & 6 \\
\hline $\mathbf{5}$ & $\begin{array}{c}\text { HAp/Porous PLGA } \\
\text { (slow quench, SQ TIPS) }\end{array}$ & $10 \%$ & 5 \\
\hline $\mathbf{6}$ & $\begin{array}{c}\text { HAp/Porous PLGA } \\
\text { (slow quench, SQ TIPS) }\end{array}$ & $25 \%$ & 5 \\
\hline
\end{tabular}

Table 3. In vitro rhBMP-2 elution scaffold groups.

\begin{tabular}{ccccc}
\hline Group & Scaffold & Local anabolic agent & Local anti-catabolic agent & $\boldsymbol{n}$ \\
\hline $\mathbf{1}$ & Collagen & $10 \mu \mathrm{g}$ rhBMP-2 & - & 3 \\
\hline $\mathbf{2}$ & $\begin{array}{c}\text { Porous PLGA } \\
\text { (slow quench, SQ TIPS) }\end{array}$ & $10 \mu \mathrm{g}$ rhBMP-2 & - & 3 \\
\hline $\mathbf{3}$ & $\begin{array}{c}\text { HAp/Porous PLGA } \\
\text { (slow quench, SQ TIPS) }\end{array}$ & $10 \mu \mathrm{g}$ rhBMP-2 & - & 3 \\
\hline $\mathbf{4}$ & $\begin{array}{c}\text { Porous PLGA } \\
\text { (slow quench, SQ TIPS) }\end{array}$ & $10 \mu \mathrm{g}$ rhBMP-2 & $0.2 \mu \mathrm{g} \mathrm{ZA}$ & 3 \\
\hline $\mathbf{5}$ & $\begin{array}{c}\text { HAp/Porous PLGA } \\
\text { (slow quench, SQ TIPS) }\end{array}$ & $10 \mu \mathrm{g}$ rhBMP-2 & $0.2 \mu \mathrm{g} \mathrm{ZA} \mathrm{(via} \mathrm{2} \mathrm{\%} \mathrm{HAp} \mathrm{)}$ & 3 \\
\hline $\mathbf{6}$ & $\begin{array}{c}\text { Porous PLGA } \\
\text { (slow quench, SQ TIPS) }\end{array}$ & $10 \mu \mathrm{g}$ rhBMP-2 & $2 \mu \mathrm{g} \mathrm{ZA}$ & 3 \\
\hline & & & &
\end{tabular}

Table 4. In vitro radiolabelled ZA elution scaffold groups.

\begin{tabular}{ccccc}
\hline Grp & Polymer scaffold & Local anabolic agent & Local anti-catabolic agent & $\boldsymbol{n}$ \\
\hline $\mathbf{1}$ & $\begin{array}{c}\text { Porous PLGA } \\
\text { (slow quench, SQ TIPS) }\end{array}$ & $10 \mu \mathrm{g}$ rhBMP-2 & - & 3 \\
\hline $\mathbf{2}$ & $\begin{array}{c}\text { Porous PLGA } \\
\text { (slow quench, SQ TIPS) }\end{array}$ & $10 \mu \mathrm{g}$ rhBMP-2 & $0.2 \mu \mathrm{g}{ }^{14} \mathrm{C}-\mathrm{ZA}$ & 3 \\
\hline $\mathbf{3}$ & $\begin{array}{c}\text { HAp/Porous PLGA } \\
\text { (slow quench, SQ TIPS) }\end{array}$ & $10 \mu \mathrm{g}$ rhBMP-2 & $0.2 \mu \mathrm{g}{ }^{14} \mathrm{C}-\mathrm{ZA}($ via $2 \%$ HAp) & 3 \\
\hline
\end{tabular}

elution studies were conducted to characterise the scaffold architecture, mechanical properties, and drug release kinetics respectively. A range of HAp concentrations, including the $2 \% \mathrm{w} / \mathrm{w}$ used in in vivo experiments, were tested by compression (Table 2). Drug elution studies took place over 3 weeks, with rhBMP-2 being measured by enzyme-linked immunosorbent assay (ELISA) (Table 3) and ${ }^{14} \mathrm{C}$-radiolabelled ZA by scintillation counting (Table 4).

\section{Reagents}

Recombinant human Bone Morphogenetic Protein-2 (rhBMP-2) from INFUSE ${ }^{\circledR}$ Bone Graft Small Kit was purchased from Medronic (Memphis, TN, USA) and Zoledronic Acid (ZA) was purchased from AXXORA (San Diego, CA, USA). For in vitro studies, a stock solution of ${ }^{14} \mathrm{C}$ radiolabelled ZA $\left({ }^{14} \mathrm{C}-\mathrm{ZA}\right)$ with a specific activity of $7.027 \mathrm{MBq} / \mathrm{mg}$ was supplied by Novartis Pharma (Basel, Switzerland).

Poly-D,L-lactic-acid (PDLLA) biodegradable polymer (inherent viscosity $0.55-0.75 \mathrm{dl} / \mathrm{g}$, average MW 75,000120,000; Sigma-Aldrich, Sydney, Australia) and organic solvent, ethyl acetate (analytic reagent grade, Chem Supply, Port Adelaide, Australia) were used for the fabrication of the solid PDLLA discs. Poly(D,L-lactide-co-glycolide)
(PLGA) biodegradable polymer (lactide:glycolide ratio of 50:50 and inherent viscosity $0.95-1.20 \mathrm{dl} / \mathrm{g}$, Durect, Lactel $^{\circ}$, Pelham, AL, USA) and solvent 1,4-dioxane (99\% ACS reagent, Gliwice, Poland) were used for the fabrication of porous PLGA scaffolds. Collagen from INFUSE $^{\circledR}$ Bone Graft Small Kit (Medronic, Memphis, TN, USA) was used as supplied.

Precalcined hydroxyapatite (HAp) microparticles with an average diameter $\sim 1.5 \mu \mathrm{m}$ were used (P149, Plasma Biotal, Buxton, Derbyshire, UK). Particles were agglomerates of acicular nanoparticles (diameter $\sim 100 \mathrm{~nm}$ x $250 \mathrm{~nm}$ ) (Ruys et al., 1995). ZA was adsorbed to HAp following protocol previously published by Seshima et al. (Seshima et al., 2006) and Shi et al. (Shi et al., 2009). Briefly, ZA/sterile water solution $(1 \mathrm{mg} / \mathrm{mL})$ was incubated with HAp $\left(37^{\circ} \mathrm{C}\right.$ water bath for $\left.24 \mathrm{~h}\right)$, filtered, and the remaining ZA-HAp vacuum-dried (for $8 \mathrm{~h}$ at $-70 \mathrm{kPa}$ and $\left.45^{\circ} \mathrm{C}\right)$.

\section{Production of solvent-cast PDLLA discs}

Solid solvent-cast PDLLA discs containing $10 \mu \mathrm{g}$ rhBMP-2 were manufactured as previously described (Yu et al., 2010b). In brief, rhBMP-2 and PDLLA/ethyl acetate solutions were mixed by vortex and sonication. The solvent was vacuum evaporated and the remaining rhBMP-2/ 
PDLLA was compressed into disks ( $3 \mathrm{~mm}$ diameter and $1 \mathrm{~mm}$ height) and UV-sterilised for $2 \mathrm{~min}$.

\section{Production of porous PLGA scaffolds by thermally induced phase separation}

Porous PLGA scaffolds containing $10 \mu \mathrm{g}$ rhBMP $-2 \pm \mathrm{ZA}$ \pm HAp were produced by a modified thermally induced phase separation (TIPS) method from Cao et al. (Cao et al., 2004; Cao et al., 2006a; Cao et al., 2006b) and Jack et al. (Jack et al., 2009). In brief, a PLGA/dioxane stock solution was diluted with dioxane-containing drug \pm HAp solutions to give a final concentration of $10 \% \mathrm{w} / \mathrm{v}$. The polymer + drug/dioxane solutions were mixed by vortex and sonication. Composite HAp/PLGA scaffolds were loaded with HAp at $2 \% \mathrm{w} / \mathrm{w}$. The final solutions were transferred into glass moulds and quenched in a $-18{ }^{\circ} \mathrm{C}$ freezer (quick quench, QQ) or underwent controlled cooling from $25^{\circ} \mathrm{C}$ to $-10{ }^{\circ} \mathrm{C}$ at a rate of $-0.5^{\circ} \mathrm{C} / \mathrm{min}$ (slow quench, SQ). Once removed from glass moulds, quenched scaffold rods were placed under low vacuum $(8 \mathrm{~h}, 7.3 \mathrm{x}$ $10^{-5} \mathrm{KPa}$ ) for solvent removal. Vacuum-dried scaffold rods were sliced into discs ( $3 \mathrm{~mm}$ diameter and $1 \mathrm{~mm}$ height) with a stainless steel blade (N35, Feather Safety Razor, Osaka, Japan). The disks were UV sterilised for $2 \mathrm{~min}$.

\section{Scanning electron microscopy}

Surfaces of all porous PLGA scaffolds groups (including those with HAp) were visualised with scanning electron microscopy (SEM). Two scaffolds were used per scaffold group. Samples were cut with a stainless steel blade to produce transaxial and sagittal surfaces. Samples were adhered to standard SEM stubs and sputter-coated with gold/palladium $(11 \mathrm{~nm})$. Secondary electron images were captured with Philips XL 30 CP microscopy system (Philips, Sydney, Australia) at $15 \mathrm{kV}$.

\section{Compression testing of PLGA \pm HAp scaffolds}

The mechanical effect of HAp addition to PLGA at various percentage weight compositions $(0,1,2,5,10$ and $25 \% \mathrm{w} / \mathrm{w}$ ) was determined by compressive testing of porous PLGA TIPS (slow quenched) scaffolds. Cylindrical scaffolds (10 $\mathrm{mm}$ diameter x $5 \mathrm{~mm}$ height) were compressed with an Instron Mechanical Tester 5944 with a $100 \mathrm{~N}$ load cell (Instron, Norwood, MA, USA). All tests were performed at $0.10 \mathrm{~min}^{-1}$ strain rate (i.e., cross head rate of $0.5 \mathrm{~mm} / \mathrm{min}$ ). An average of $n=5$ per scaffold group was tested (Table 2). Compressive strength (MPa) and compressive modulus $(\mathrm{MPa})$ were collected with BlueHill 3 software.

\section{Animal care and surgery}

Female C57BL6/J mice were purchased from the Animal Resources Centre (Perth, WA, Australia) and used at 8-10 weeks (average weight $18 \mathrm{~g}$ ) for all in vivo studies. Animals were allowed 1 week acclimatisation to local vivarium conditions prior to surgery. Animal studies were approved by the local animal ethics committee (AEC, K294/10) and animals were given chow and water ad libitum.

Surgical introduction of scaffolds/discs was performed based on a previously published methodology (Yu et al., 2010b). Anaesthesia was induced with an intraperitoneal injection of $35 \mathrm{mg} / \mathrm{kg}$ ketamine and $4.5 \mathrm{mg} / \mathrm{kg}$ xylazine and maintained with inhaled isoflurane. In a modification of the published model, for the first study 4 implants were introduced to the dorsal musculature of mice containing doses of $0,5,10$ and $20 \mu \mathrm{g}$ rhBMP-2 (Table 1). For the second study, a single implant was introduced to the hind limb, as per our standard model (Yu et al., 2010b). Each scaffold contained $10 \mu \mathrm{g}$ rhBMP- $2 \pm 0.2$, or $2 \mu \mathrm{g}$ zoledronic acid (ZA) $\pm 2 \% \mathrm{w} / \mathrm{w}$ HAp (Table 1 ). Following surgery, animals were allowed to recover and monitored postoperatively and given saline and buprenorphine $(0.05 \mathrm{mg} /$ $\mathrm{kg}$ ) to manage dehydration and post-operative pain and monitored by weekly weighing. A subset of animals dosed with $0.1 \mathrm{mg} / \mathrm{kg} \mathrm{ZA}$ by subcutaneous injection (s.c.) if systemic dosing was indicated. This ZA dose is considered comparable to that used for clinical management of osteoporosis dose on a milligram per kilogram basis, and has been used previously by our group (Smith et al., 2004; Little et al., 2005). Animals were euthanised by $\mathrm{CO}_{2}$ asphyxiation at 3 weeks after surgery.

\section{Radiographic imaging and micro-computed tomography (microCT)}

Ectopic bone nodule placement relative to surrounding bone structure was assessed in two-dimensions by digital X-ray (Faxitron X-ray Corp, Wheeling, IL, USA) at $27 \mathrm{kV}$ and $2 \times$ magnification). Samples were excluded from analysis if the ectopic bone nodule had fused with an adjacent bone structure (e.g., vertebrae or femur), or if the scaffold was found to have shifted out of the muscle pouch subsequent to surgery.

Three-dimensional (3D) measurement and analysis was carried out by microCT. Samples were scanned in $70 \%$ ethanol with SkyScan 1174 compact $\mu \mathrm{CT}$ scanner (SkyScan, Kontich, Belgium) at $11.97 \mu \mathrm{m}$ pixel resolution and with $0.5 \mathrm{~mm}$ aluminium filter, $50 \mathrm{kV}$ X-ray tube voltage, $800 \mu \mathrm{A}$ tube electric current, and $4500 \mathrm{~ms}$ scanning exposure time. MicroCT images were reconstructed using NRecon (version 1.6.1.7, SkyScan) and three dimensional assessments were conducted with CTAnalyser software (version 1.10.9.0, SkyScan). The primary outcome measurement was bone volume $\left(\mathrm{BV}, \mathrm{mm}^{3}\right)$. Secondary outcome measurements for the hind-limb muscle pouch studies included bone tissue mineral density and pellet nodule volume. Bone tissue mineral density (bone TMD, $\mathrm{mg} / \mathrm{cm}^{3}$ of hydroxyapatite) was as defined by Bouxsein et al. (Bouxsein et al., 2010) as the material density of bone tissue region only. The bone tissue was defined as calcified tissue detected by microCT using predetermined thresholds as shown in Fig. 1A. The pellet nodule volume $\left(\mathrm{PNV}, \mathrm{mm}^{3}\right)$ was defined as the total volume occupied by the nodule, including the outer cortical shell and inner bone and pseudo marrow cavity. This is visually represented in Fig. 1B.

Representative three-dimensional bone nodule reconstructions were generated from ectopic bone samples with BV closest to the group's mean. Samples were reconstructed with transaxial slices $(0.42 \mathrm{~mm})$ from the pellet nodule's mid-section with CTVol Realistic Visualisation software (version 2.1.0.0, SkyScan). 


\section{Histological analysis of bone formation}

Samples were harvested post-mortem, fixed in $4 \%$ paraformaldehyde, and stored in $70 \%$ ethanol for radiographic and histological analysis. Samples were decalcified at $4{ }^{\circ} \mathrm{C}$ on a shaker in $0.34 \mathrm{M}$ EDTA ( $\mathrm{pH} 8.0$ ) containing $0.5 \%$ paraformaldehyde for 3 days, followed by 27 days in 0.34 M EDTA changed every 3 days. Decalcified samples were processed to paraffin. Transaxially halved samples were embedded in paraffin. $0.5 \mathrm{~mm}$-thick sections were cut using a Leica RM 2155 Microtome (Leica Microsystems, Wetzlar, Germany). Sections were stained with alcian blue and picrosirius red for cartilage and bone. Stained sections were scanned with ScanScope digital slide scanner (Aperio Technologies, Vista, CA, USA), and images were captured with ImageScope (Aperio Technologies). Observational histology was conducted on all samples from the hind-limb muscle pouch studies.

\section{In vitro rhBMP-2 and ${ }^{14} \mathrm{C}-\mathrm{ZA}$ elution analysis}

Release of rhBMP-2 and radiolabelled ${ }^{14} \mathrm{C}-\mathrm{ZA}$ from porous PLGA TIPS (slow quenched) scaffolds (3 mm diameter and $1 \mathrm{~mm}$ height) was measured over 3 weeks as per Table 3 and Table $4 ; n=3$ scaffolds were measured per group. Samples were incubated at $37^{\circ} \mathrm{C}$ in Protein LoBind tubes (Eppendorf, Stevenage, UK) containing $2 \mathrm{~mL}$ of elution buffer ( $1 \%$ bovine serum albumin/phosphate buffered saline, BSA/PBS) formulated to prevent adsorption to the vessel. At time points of $1 \mathrm{~h}, 1$ day $(24 \mathrm{~h}), 1$ week (168 h), and 3 weeks $(504 \mathrm{~h})$, scaffolds were transferred to new tubes containing fresh elution buffer. Collected samples were stored at $-20{ }^{\circ} \mathrm{C}$.

The amount of rhBMP-2 drug released was quantified using a Quantikine ${ }^{\circledR}$ BMP-2 Immunoassay (PDBP200, R\&D Systems, Wiesbaden, Germany) as per the manufacturer's instructions. ${ }^{14} \mathrm{C}-\mathrm{ZA}$ was measured with Tri-Carb scintillation counter (Packard, MN, USA) using scintillation cocktail (5 mL Ultima Gold DIPN, PerkinElmer, Waltham, MA USA) and counted in $20 \mathrm{~mL}$ Pico Prias polyethylene vials (Perkin-Elmer). Remaining ${ }^{14} \mathrm{C}$-ZA was measured by solubilising the residual scaffold with $2 \mathrm{~mL}$ ethyl acetate. Values were compared to a standard curve generated from ${ }^{14} \mathrm{C}$-ZA standards.

\section{Statistical analyses}

Statistical analyses of in vitro drug elution data was conducted with one-way ANOVA with Dunnett's post-hoc test. Statistical significance was set at $\alpha<0.05$. Analysis
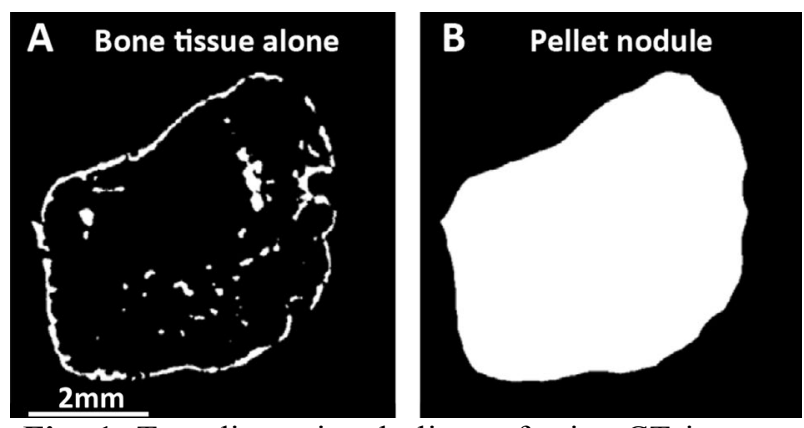

Fig. 1. Two-dimensional slices of microCT images representing (A) the bone tissue region versus $(\mathbf{B})$ the pellet nodule region. Scale bar $=2 \mathrm{~mm}$.

for mechanical testing was conducted with non-parametric tests (Kruskal Wallis and Mann Whitney U). For analyses of microCT data from animal studies, non-parametric statistical tests (Kruskal Wallis and Mann Whitney U) were carried out, as these complex biological models could not be assumed to follow a normal distribution. All tests were performed using SPSS Statistics version 17 (SPSS, Chicago, IL, USA). Statistical significance was set at $\alpha<0.05$.

\section{Results}

\section{SEM analysis of porous PGLA scaffolds generated by TIPS}

The surface morphology of TIPS-fabricated scaffolds was characterised by scanning electron microscopy (SEM) to reveal a highly porous structure with interconnected pores. Slow quench (SQ) TIPS scaffolds showed an isotropic pore structure while quick quench (QQ) TIPS scaffolds demonstrated an anisotropic (aligned) pore structure, with round and tubular-shaped pores directed to the centre of the scaffold. Pore structure was not affected by the presence or absence of rhBMP-2 or HAp microparticles (Fig. 2). The scaffold porosity was $90 \%$. The pore size diameter range of SQ scaffold loaded with $10 \mu \mathrm{g}$ rhBMP-2 $\pm \mathrm{ZA}(0.2 \mu \mathrm{g}$ and $2 \mu \mathrm{g}) \pm 2 \% \mathrm{w} / \mathrm{w}$ HAp was $20-200 \mu \mathrm{m}$ (average pore diameter $70 \mu \mathrm{m})$.

\section{Compression testing of PLGA \pm HAp scaffolds}

The effect of HAp addition on the mechanical properties of porous PLGA scaffolds was examined by compression
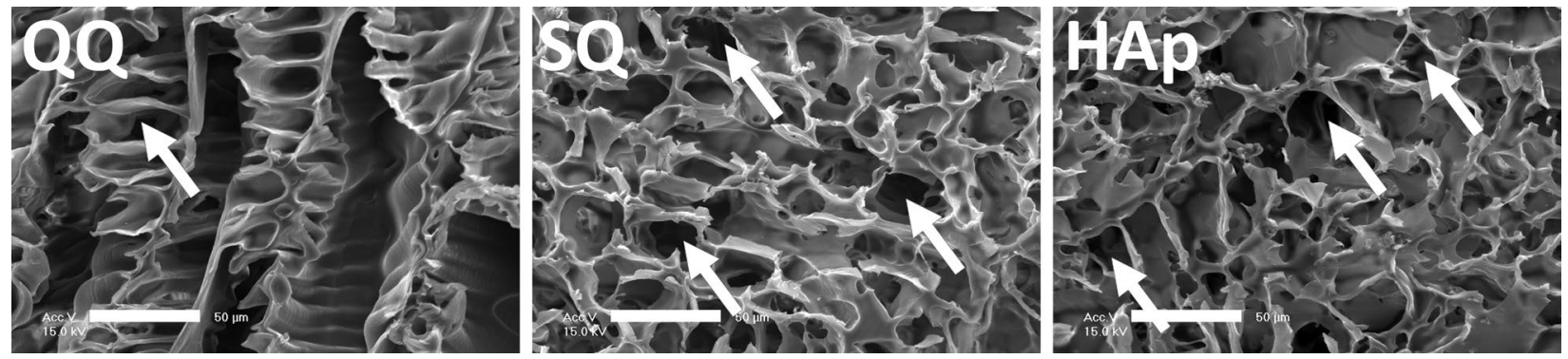

Fig. 2. Representative SEM images of the porous TIPS PLGA scaffold architecture. Examples of quick-quenched (QQ) scaffolds, slow-quenched (SQ) scaffolds, and SQ scaffolds with hydroxyapatite microparticles (HAp) are shown. Arrowheads highlight the channels interconnecting adjacent pores. Scale bar $=50 \mu \mathrm{m}$. 

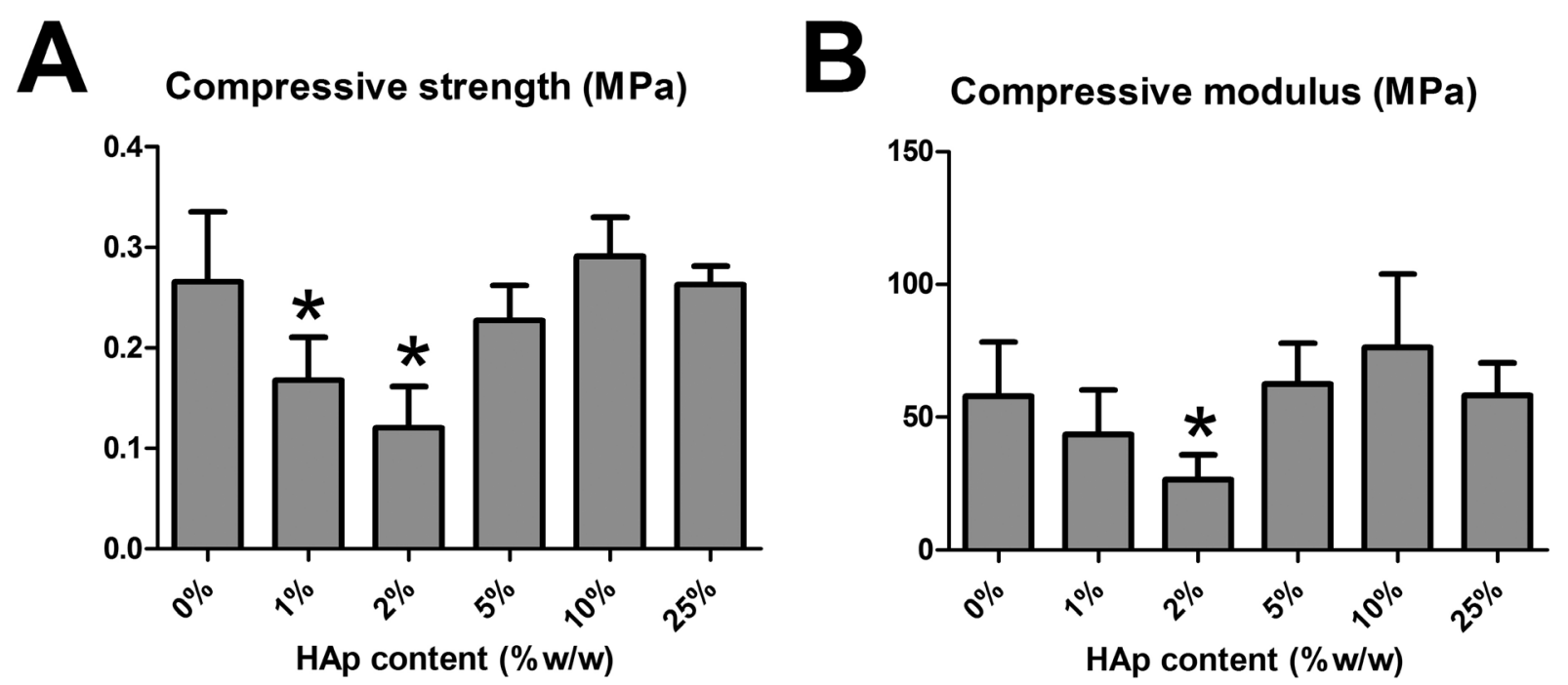

Fig. 3. Compressive properties of porous PLGA scaffolds $\pm \operatorname{HAp}(0,1,2,5,10$ and $25 \% \mathrm{w} / \mathrm{w})$. (A) Compressive strength and (B) compressive modulus. Error bars represent standard deviation and $* p<0.05 v s$. PLGA scaffold alone.

\section{Bone volume (BV, $\left.\mathrm{mm}^{3}\right)$}

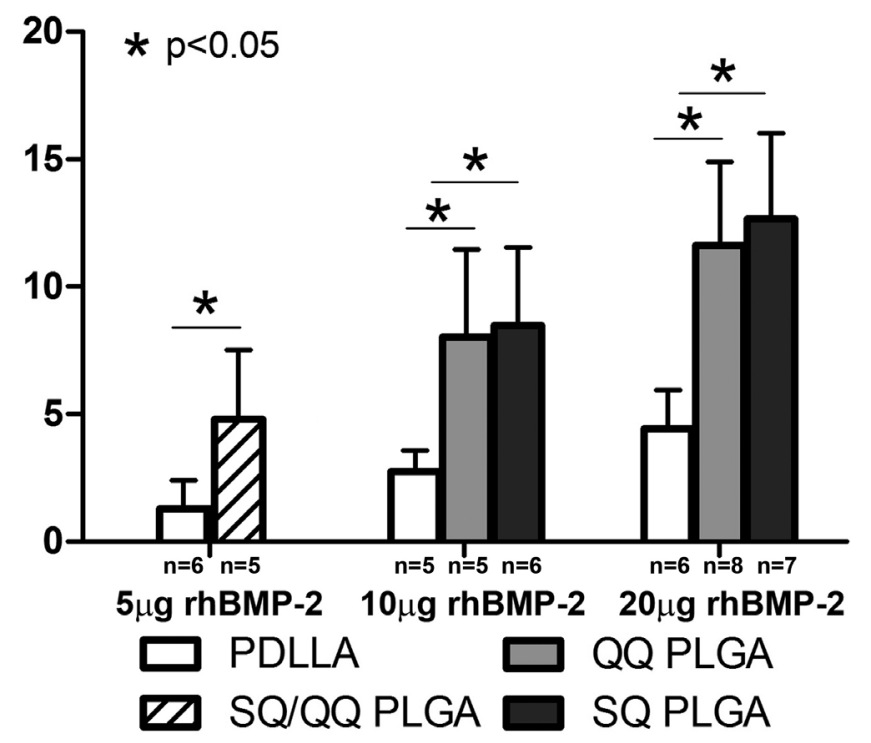

Fig. 4. Bone volume $\left(\mathrm{BV}, \mathrm{mm}^{3}\right)$ of ectopic bone nodules at 3 weeks post-scaffold insertion. ${ }^{*} p<0.05 v s$. solid PDLLA disc of same rhBMP-2 dose. Error bars represent standard deviation. $n=$ number of samples remaining following exclusions.

testing. Various HAp percentage weight compositions $(0,1,2,5,10$ and $25 \% \mathrm{w} / \mathrm{w})$ were tested. Compared to porous PLGA alone scaffolds, the addition of $1 \%$ and $2 \%$ HAp reduced compressive strength (37\% and $55 \%$ respectively, $p<0.05)$. A $54 \%$ reduction in compressive modulus $(p<0.01)$ was found with $2 \% \mathrm{w} / \mathrm{w}$ HAp addition. In contrast, no change in compressive properties was found with higher percentage weight compositions at 5, 10 or $25 \%$ w/w (Fig. 3).

Comparison of porous PLGA scaffolds versus solid PDLLA discs

To compare the porous PGLA scaffolds versus the solid PDLLA discs used previously by us (Yu et al., 2010b), delivery of a range of rhBMP-2 doses were assessed in an in vivo ectopic bone formation assay. No bone nodules formed in the absence of rhBMP-2. BV was found to be significantly higher for the PGLA TIPS scaffolds groups for all rhBMP-2 doses $(160-270 \%$ increase, $p<0.05)$ (Fig. 4). The bone induced by $5 \mu \mathrm{g}$ rhBMP-2/porous PLGA(QQ/ SQ) TIPS scaffold was comparable to $20 \mu \mathrm{g}$ rhBMP-2/ solid PDLLA discs (N.S. $p=0.89$ ). Sub-group analysis of SQ versus QQ scaffolds of the $10 \mu \mathrm{g}$ and $20 \mu \mathrm{g}$ rhBMP-2 groups showed no significant difference in BV between the two quenching methods.

3D microCT reconstructions of ectopic bone nodules illustrated differences between the two scaffold/pellet designs (Fig. 5). All delivery systems featured a cortical 
Fig. 5. Representative microCT $3 \mathrm{D}$ reconstructions of rhBMP-2 induced bone nodules resulting from solid PDLLA scaffolds and porous PLGA quick quench (QQ)/ slow quench (SQ) scaffolds. Scale bar $=5 \mathrm{~mm}$.

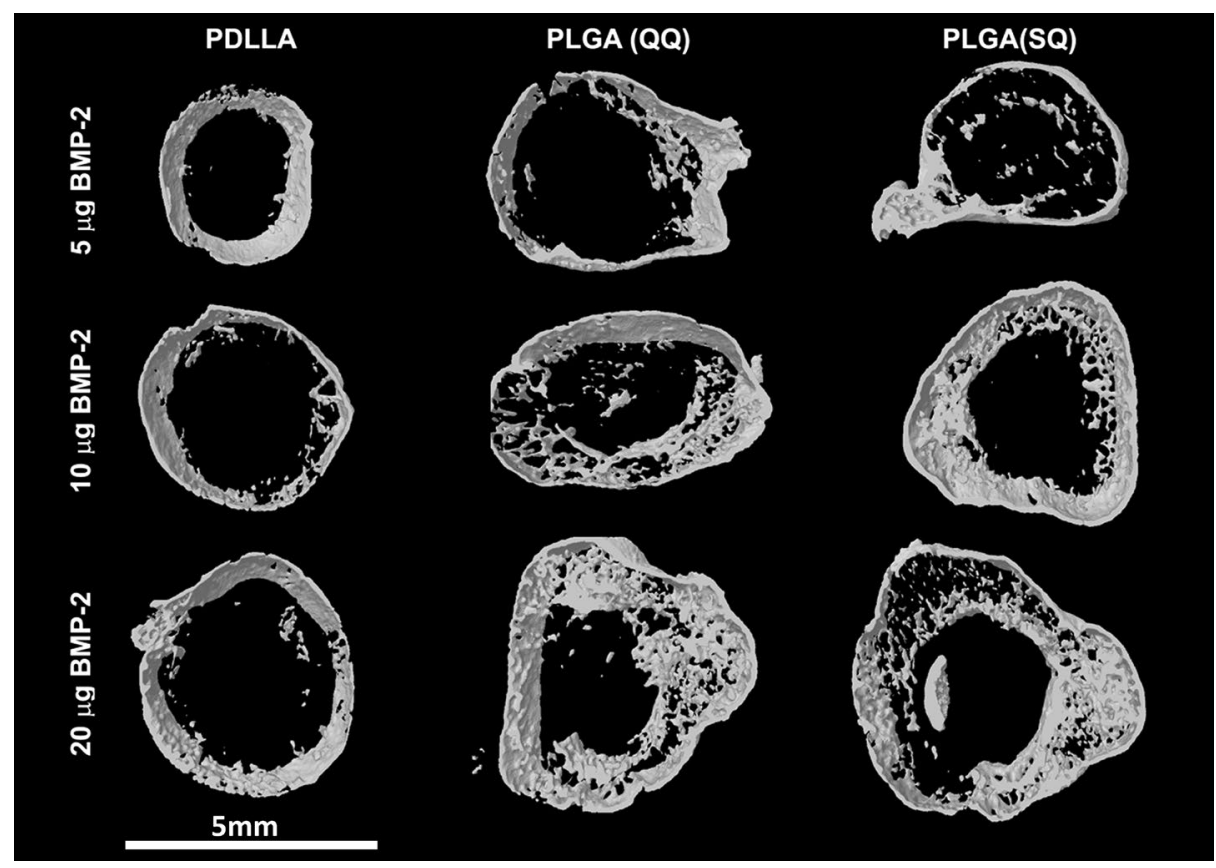

Fig. 6. Histological images of alcian blue and picrosiriusstained sections. (A) solid PDLLAdisc, (B) porous PLGA QQ scaffold, and (C) porous PLGA SQ scaffold. Higher magnifications are shown in A', B', and C' respectively. Scale bar $=500 \mu \mathrm{m}$. PDLLA residue are bound by arrowheads.
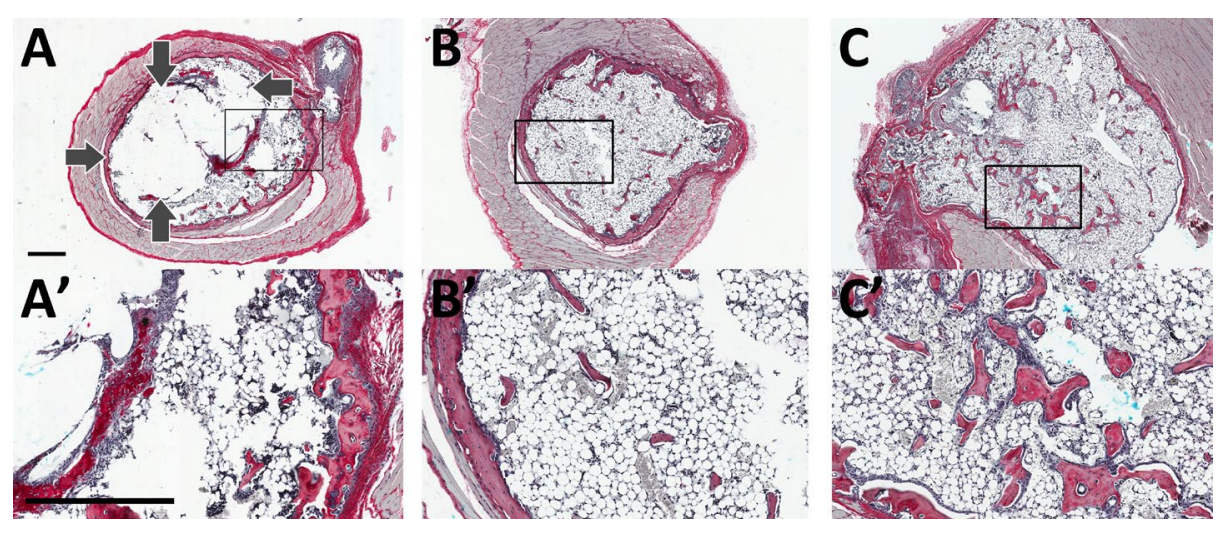

outer shell, but the PGLA TIPS pellets showed significantly more internal trabeculae than the solid PDLLA discs. Additionally, the PDLLA group had poor biodegradation and the centre of these specimens contained significant residual polymer. These observations were further confirmed on histological sections with alcian blue and picrosirius red staining (Fig. 6).

\section{Local co-delivery of rhBMP-2 and bisphosphonate via porous PLGA scaffolds}

The capacity of local bisphosphonate delivery to enhance rhBMP-2 induced bone was further refined based on using $10 \mu \mathrm{g}$ rhBMP-2 in the PGLA (SQ TIPS) scaffolds. In the hind-limb model, net bone at 3 weeks was significantly increased with local co-delivery of $2 \mu \mathrm{g}$ ZA (400\% increase in BV vs. rhBMP-2 alone, $p<0.01)$. Systemic ZA $(0.1 \mathrm{mg} / \mathrm{kg})$ co-treatment also resulted in increased bone $(610 \%$ increase in BV versus rhBMP-2 alone, $p<0.01$ ), and this was comparable to $2 \mu \mathrm{g}$ local ZA (N.S, $p=0.34)$. The lower dose of $0.2 \mu \mathrm{g} Z \mathrm{ZA}$ did not alter net bone formation (7 \% BV decrease, N.S) (Fig. 7).

Pellet nodule volume $\left(\mathrm{PNV}, \mathrm{mm}^{3}\right)$, which reflects the overall nodule size, was significantly higher with $2 \mu \mathrm{g}$ local ZA (110\% increase, $p<0.01)$, but not with $0.1 \mathrm{mg} /$ kg systemic ZA (45 \% increase, N.S) (Fig. 8). These ZA dosing regimens also led to significant increases in bone tissue mineral density (bone TMD) compared to rhBMP-2 alone nodules ( $9 \%$ increase, $p=0.01$ and $23 \%$ increase, $p<0.01$ for local and systemic respectively) (Fig. 9). Representative microCT 3D reconstructions were used to visualise these findings and images representing the median BV for each group are shown (Fig. 10).

Observational histology of bone regions confirmed that there was considerable retention of the primary spongiosa in the in the $2 \mu \mathrm{g}$ local ZA group and $0.1 \mathrm{mg} / \mathrm{kg}$ systemic ZA group (data not shown).

\section{Co-delivery of rhBMP-2 and ZA-adsorbed HAp microparticles}

An additional group included in the hind-limb model was scaffolds containing $10 \mu \mathrm{g}$ rhBMP- $2+0.2 \mu \mathrm{g}$ ZA $+2 \% \mathrm{w} / \mathrm{w}$ HAp where the ZA was pre-adsorbed to the hydroxyapatite. It was hypothesised that this may prevent or ameliorate the burst release of ZA from the scaffolds and thus lead to improved biological outcomes. While $0.2 \mu \mathrm{g}$ ZA was not sufficient to BV compared to controls, the dose pre-adsorbed onto HAp led to significant increases in BV compared to rhBMP-2 alone (174\% increase, $p<0.01$ ) 


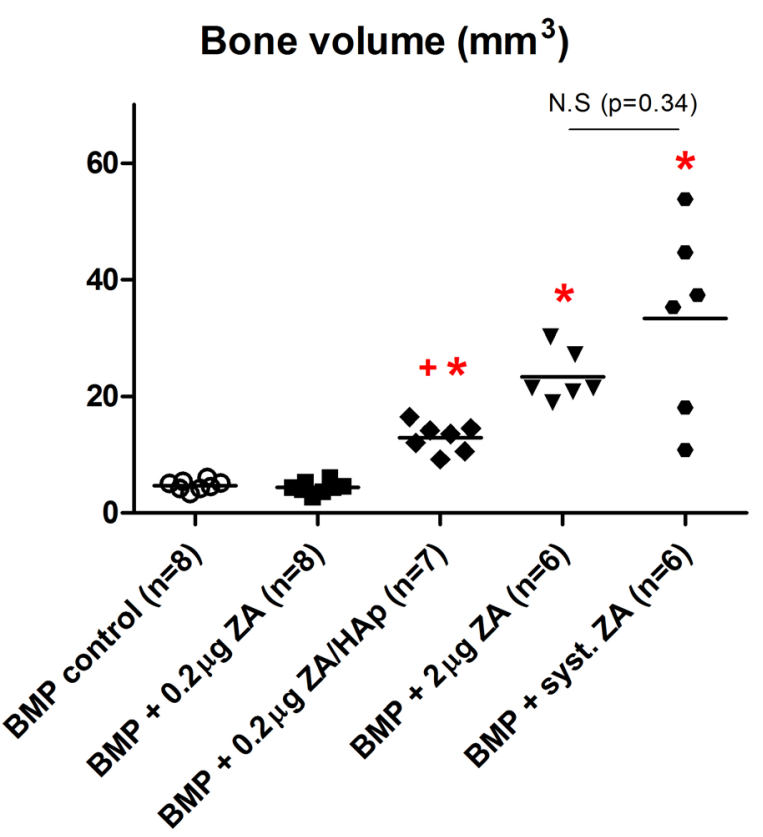

Fig. 7. Bone volume $\left(\mathrm{BV}, \mathrm{mm}^{3}\right)$ of ectopic bone nodules at 3 weeks post-scaffold insertion. ${ }^{*} p \leq 0.01 v s$. BMP controls and $+p<0.01 v s$. BMP $+0.2 \mu \mathrm{g}$ ZA. $n=$ number of samples analysed after exclusions.

and local $0.2 \mu \mathrm{g}$ ZA (195\% increase, $p<0.01)$ (Fig. 7). The pellet nodule volume $\left(\mathrm{PNV}, \mathrm{mm}^{3}\right)$ of local $0.2 \mu \mathrm{g}$ $\mathrm{ZA} \pm \mathrm{HAp}$ was comparable to rhBMP-2 alone (Fig. 8). Comparable increases were seen in bone TMD compared to rhBMP-2 alone $(13 \%, p<0.01)$ and local $0.2 \mu \mathrm{g}$ ZA (11 \%, $p=0.02)$ (Fig. 9). MicroCT reconstructions revealed that co-treatment of rhBMP-2 and HAp-ZA led to increased bone sheath thickness and increased bone in-growth (Fig. 10).

\section{Elution of rhBMP-2 and ZA from porous PLGA scaffolds}

The rhBMP-2 release of PLGA scaffolds was modelled in vitro over 3 weeks and quantified by ELISA. In all groups there was a burst release within the first hour (55-65\% of the total rhBMP-2 released), which was followed by a sustained drug release (Fig. 11A). The inclusion of HAp did not affect the rhBMP-2 release. Nevertheless, the total release of rhBMP-2 represented less than $2 \%$ of the total rhBMP-2 incorporated into the scaffold, although the scaffolds did not undergo any biodegradation comparable to that seen after surgical implantation. Porous collagen scaffold used in clinical delivery was used as a control, and the amount of rhBMP-2 released from collagen scaffold was significantly higher than PLGA TIPS scaffold at all time-points (390\% at $1 \mathrm{~h}$ and average of $170 \%$ from 24-504 h, $p<0.01$ ), but again less than $10 \%$ of the total rhBMP-2 originally added was detected by ELISA.

To test the in vitro release of radiolabelled ${ }^{14} \mathrm{C}-\mathrm{ZA}$ and examine the effects of HAp inclusion, eluents were measured by scintillation counting. A group lacking ${ }^{14} \mathrm{C}-\mathrm{ZA}$ was included to determine background. In PLGA scaffolds containing $10 \mu \mathrm{g} \mathrm{BMP}+0.2 \mu \mathrm{g}{ }^{14} \mathrm{C}-\mathrm{ZA}, 51 \%$ of the total $\mathrm{ZA}$ eluted was released from the BMP + ZA scaffold

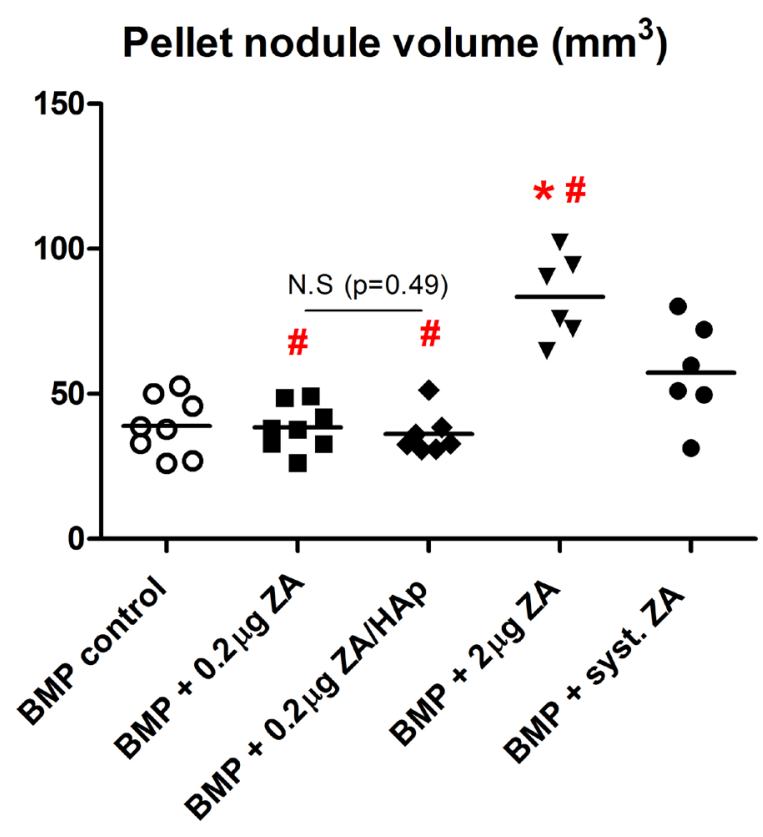

Fig. 8. Pellet nodule volume $\left(\mathrm{PNV}, \mathrm{mm}^{3}\right)$ of ectopic bone nodules at 3 weeks post-scaffold insertion. ${ }^{*} p<0.01$ vs. $\mathrm{BMP}$ controls and $\# p<0.03 v s$. BMP + systemic ZA.

\section{Tissue mineral denisty $\left(\mathrm{mg} / \mathrm{cm}^{3}\right)$}

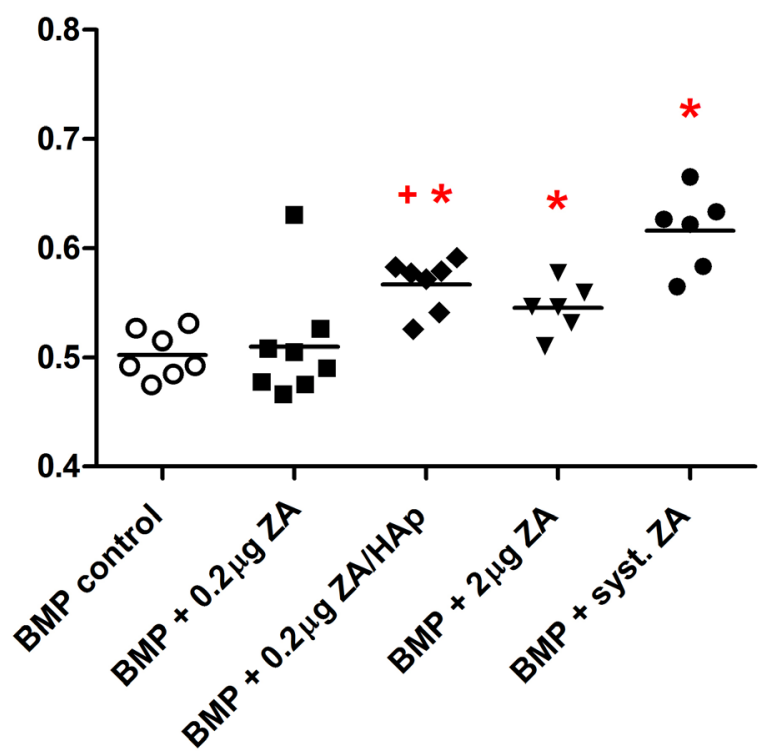

Fig. 9. Bone tissue mineral density $\left(\mathrm{TMD}, \mathrm{mg} / \mathrm{cm}^{3}\right)$ of ectopic bone nodules at 3 weeks post-scaffold insertion. ${ }^{*} p \leq 0.01 v s$. BMP control, \#p $<0.01 v s$. BMP + systemic $\mathrm{ZA}$, and $+p<0.05 v s$. BMP $+0.2 \mu \mathrm{g} \mathrm{ZA}$.

group in the first hour. In samples containing HAp, this was reduced to $29 \%$ in the first hour (Fig. 11B). By $24 \mathrm{~h}$ the groups without and with HAp had released $88 \%$ and $55 \%$ respectively. No difference was seen at the 3 week time point with all of the ${ }^{14} \mathrm{C}$-ZA detected as having been eluted from the PGLA scaffolds. The total ZA released at 3 weeks and ZA loaded per scaffold were consistent between the groups. 


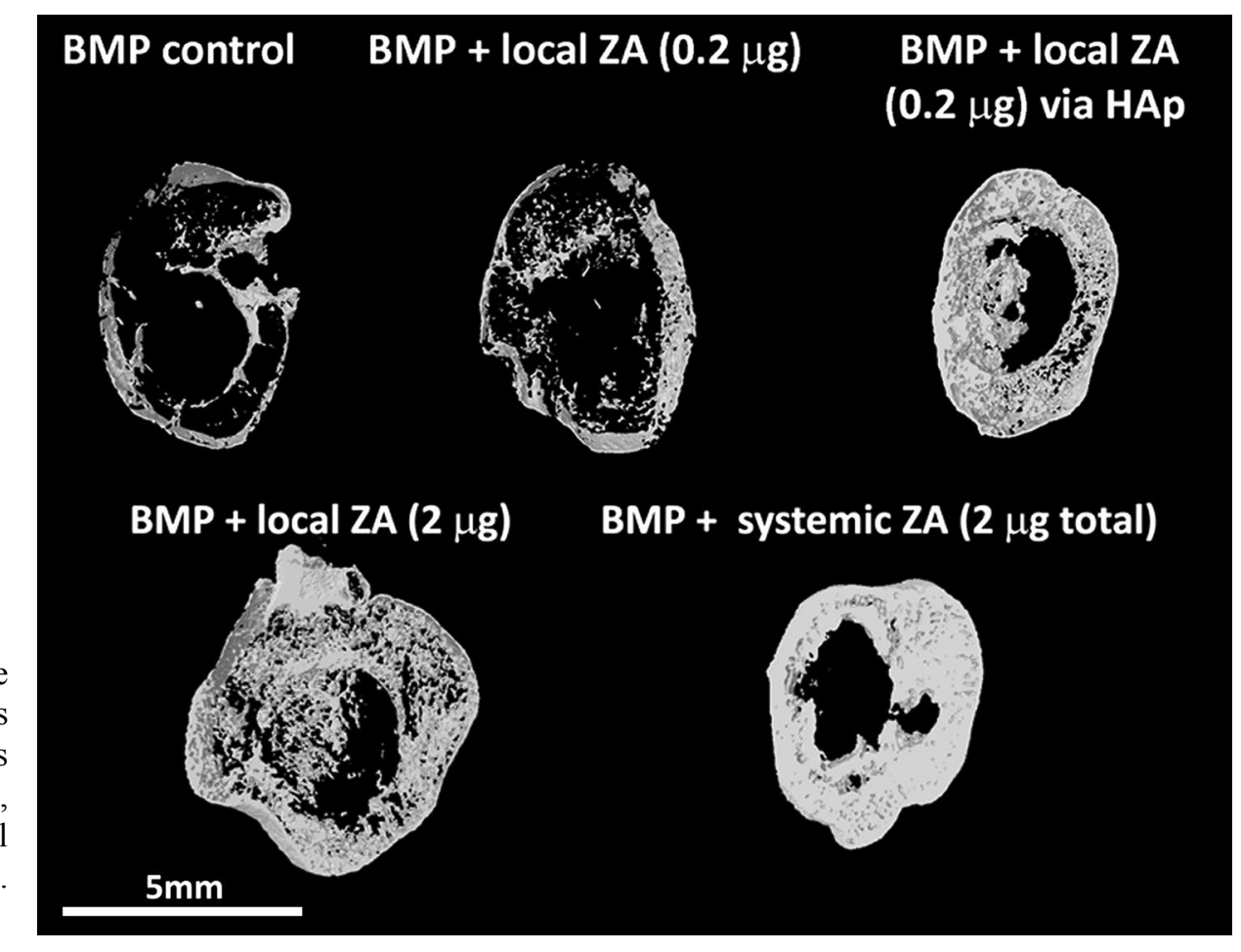

Fig. 10. Representative microCT $3 \mathrm{D}$ reconstructions of ectopic bone nodules from rhBMP-2 controls, and co-treated with local $\mathrm{ZA} \pm \mathrm{HAp}$ or systemic ZA. Scale bar $=5 \mathrm{~mm}$.

\section{Discussion}

Based on the fundamental concepts of maximising bone anabolism while minimising bone catabolism, this study describes the iterative refinement of a polymer-based scaffold for bone tissue engineering. We have previously published on the application of a solid solvent-cast PDLLA polymer disc for the co-delivery of rhBMP-7 and pamidronate (Yu et al., 2010b). However, this material showed poor biodegradation that was speculated to yield suboptimal drug release as well as potentially interfere with new bone formation in the interior of implants. Consequently, we have developed a new porous PLGA polymer delivery system for the delivery of rhBMP-2. As adjunctive agents, we have explored that addition of the 3rd generation bisphosphonate ZA to reduce bone resorption, and HAp microparticles. HAp microparticles were tested to facilitate the controlled release of ZA. HAp also has osteoconductive and anti-inflammatory potential, and thus may have positive effects on bone formation independent of ZA binding (Athanasiou et al., 1996; Calandrelli et al., 2000; Rizzi et al., 2001; Calandrelli et al., 2004; Kim et al., 2004; Jung et al., 2005; Causa et al., 2006; Rezwan et al., 2006; Yu et al., 2009). However, including a series of HAp only controls was outside the scope of this study.

This scaffold approach focuses on local co-delivery of BMP and bisphosphonate. Current clinical applications and prior tissue engineering work typically features systemic delivery of bisphosphonates, however the ability to avoid adverse effects associated with systemic dosing make local dosing an appealing alternative. Our prior study using solid PDLLA discs demonstrates proof of principle that local bisphosphonate lead to yield superior outcomes (Yu et al., 2010b), although there is an underlying potential for overdosing. Other groups have also shown effects with local high dose bisphosphonate (via PLGA scaffold or bone graft) on calvarial defect healing (Choi et al., 2007) or implant fixation (Jakobsen et al., 2007). The importance of appropriate local dosing has been further corroborated by a recent study showing that lower doses of bisphosphonate zoledronic acid could increase in bone-implant fixation while higher doses were inhibitory (Jakobsen et al., 2010). The mechanism behind adverse local effects is unclear, but could be due to toxicity (Idris et al., 2008). While it may be speculated that adsorption to HAp may reduce local toxic effects, we have not yet specifically addressed this in our model system.

Our previous work showed synergy between rhBMP-7 and local bisphosphonate (Yu et al., 2010b); however, we speculated that porous PLGA would yield superior outcomes. PLGA possesses faster degradation characteristics and an extensive FDA approval history. To further increase polymer degradation rate, porous PLGA scaffolds were fabricated by thermally phase separation technique (TIPS). TIPS is a solvent-based method that allows tailored interconnected pores of desired size and distribution (Cao et al., 2004; Cao et al., 2006a; Cao et al., 2006b) and our protocol was modified from the seminal paper of Cao et al. (Cao et al., 2004; Cao et al., 2006a; Cao et al., 2006b). The resultant scaffold achieved a 90$95 \%$ porous PLGA matrix with highly ordered cellular pore structures and high interconnectivity. Porosity and interconnectivity are important for cell migration, oxygen, nutrient and metabolite supply to cells, waste transfer, and tissue ingrowth (Guillemin et al., 1989; Mikos et al., 1994; Mooney et al., 1994; Liu and Ma, 2004; Hollister, 2005). Furthermore, the faster biodegradation rate of 50:50 PLGA compared with PDLLA (Middleton and Tipton, 2000) may affect drug release, although this could not be modelled using in vitro elution studies. 


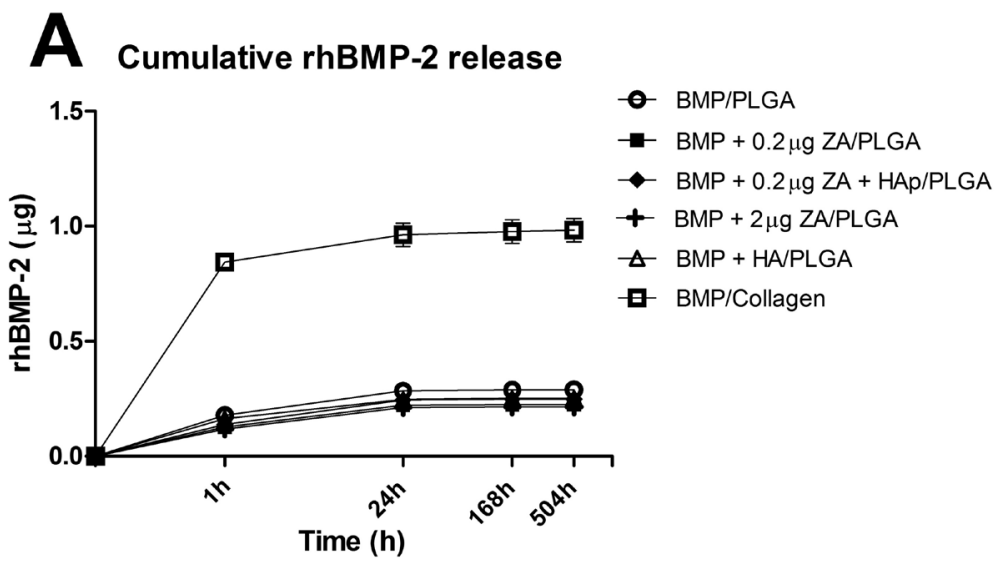

Fig. 11. In vitro drug elution characteristics over 3 weeks: (A) rhBMP-2 elution from porous $\mathrm{PLGA} \pm \mathrm{HAp}$ scaffolds and collagen scaffolds. (B) ${ }^{14} \mathrm{C}-\mathrm{ZA}$ elution from porous PLGA scaffolds \pm HAp. Error bars represent standard error mean.

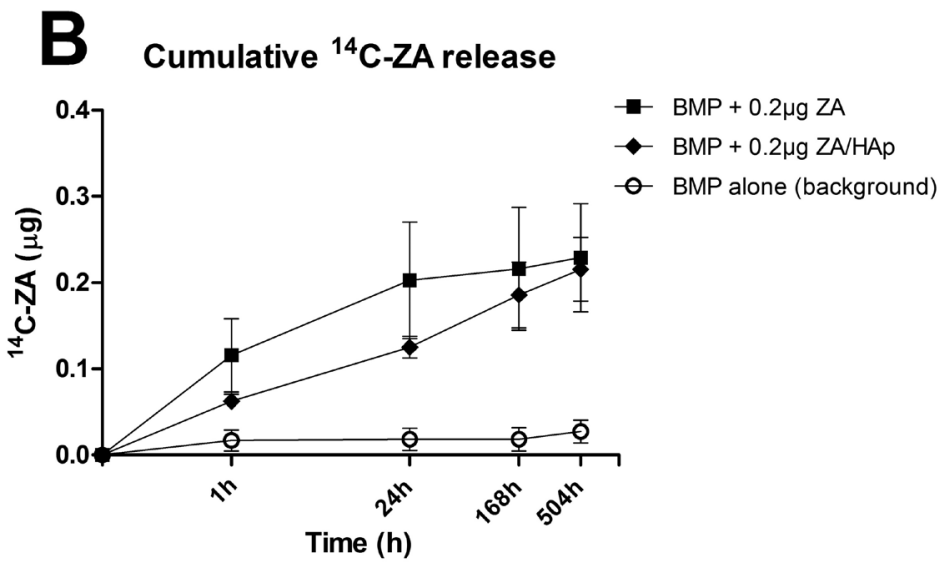

Comparison of bone formation for porous PLGA scaffolds versus solid PDLLA scaffolds showed PLGA producing more bone at all rhBMP-2 doses. The increase was 3 to 4-fold, representing a major increase in implant efficiency. PLGA scaffolds also showed increased bone in-growth. Samples from the $5 \mu \mathrm{g}$ rhBMP-2 SQ and QQ PLGA groups were unintentionally combined as one group (quick/slow quench TIPS) prior to implantation; although other rhBMP-2 doses showed no significant differences between SQ and QQ. Porous PLGA slow quench TIPS scaffolds were selected for the next phase of testing due to the capacity for future manipulation of pore structure by controlling the cooling rate.

Next, anabolic and anti-catabolic synergy was explored using ZA doses that were predicted to be below the threshold for adverse effects on bone formation. A consistent $10 \mu \mathrm{g}$ rhBMP-2 dose was used to induce ectopic bone formation. The $2 \mu \mathrm{g}$ local ZA dose significantly increased BMPinduced bone formation and bone mineral density with comparable bone volume to $0.1 \mathrm{mg} / \mathrm{kg}$ systemic ZA (i.e., total dose of $2 \mu \mathrm{g} Z \mathrm{ZA}$ ). Thus, local delivery could approach the efficacy of systemic delivery without the potential risks associated with systemic dosing. These data were consistent with previous studies showing enhancement of BMP-induced bone formation with bisphosphonate codelivery (Jeppsson et al., 2003; Chen et al., 2004; Chen et al., 2006; Jakobsen et al., 2007; Jakobsen et al., 2010; Yu et al., 2010b; Belfrage et al., 2011). This is likely due to bisphosphonate binding or becoming incorporated into the newly formed and unloaded bone and preventing its resorption. We have previously shown that local dosing with pamidronate can reduce TRAP+ cells in a rhBMP-7 induced bone formation model (Yu et al., 2010b). A similar study using local rhBMP and systemic bisphosphonate, incandronate also showed reduced osteoclast number (Gong et al., 2003).

Finally, we explored the addition of HAp microparticles for pre-adsorption of ZA and incorporation into the polymer scaffold. Since bisphosphonates have an affinity for calcium phosphate, in both synthetic HAp and natural HAp in bone (Coathup et al., 2001), it was hypothesised that ZA-bound HAp could delay release or even be preferentially phagocytosed by osteoclasts (Coathup et al., 2001). Consistent with this concept, pre-adsorption of $0.2 \mu \mathrm{g}$ ZA onto $2 \% \mathrm{w} / \mathrm{w}$ HAp led to a significant 2.7-fold increase in bone volume at 3 weeks compared to rhBMP-2 alone and rhBMP- $2+0.2 \mu \mathrm{g} \mathrm{ZA}$.

Studies have shown bisphosphonate release from HAp to be at a controlled rate (Seshima et al., 2006) and indeed, we saw a trend towards slower release of ${ }^{14} \mathrm{C}$ ZA from porous PLGA scaffolds in our in vitro studies. Interestingly, the elution of ${ }^{14} \mathrm{C}$-ZA was largely complete by 3 weeks, with all groups showing $\sim 100 \%$ elution and no radioactivity could be detected in the residual pellet. In contrast, rhBMP-2 elution was significantly less in all groups, including collagen scaffold controls. One 
explanation for this discrepancy could be the relative sizes of the molecules, although it is possible that rhBMP-2 could degrade in vitro so that total activity detected was significantly less than the original rhBMP-2 added.

The addition of $1 \% \mathrm{w} / \mathrm{w}$ HAp to porous PLGA reduced the scaffold's compressive strength $(37 \%, p<0.05)$, while $2 \% \mathrm{w} / \mathrm{w}$ HAp addition led to reductions in compressive strength and compressive modulus (54\% and $55 \%$ respectively, $p<0.01$ ). In contrast, Jack et al. (Jack et al., 2009) reported a 3-fold increase in compressive modulus with $2 \% \mathrm{w} / \mathrm{w}$ nano-sized HAp addition to porous polymeric scaffolds, although the HAp size, polymer type, and quenching regime differed to our study. In this study, it was surmised that the decrease in compressive properties found in the 1-2\% w/w HAp groups was due to the insufficient bonding between HAp within the polymer matrix. Dispersion of HAp particles may attribute to this; however, uniform HAp distribution was ensured during the polymer fabrication. Furthermore, a precursor study by Jack et al. demonstrated uniform HAp dispersion within the polymer matrix (Jack et al., 2009). In a previous study, it was found that lower HAp contents of $<30 \% \mathrm{w} / \mathrm{w}$ did not significantly increase compressive properties (Wei and $\mathrm{Ma}, 2004)$. It should be noted that during surgical handling, we observed no difference in scaffold structural integrity between porous PLGA scaffolds $\pm 2 \% \mathrm{w} / \mathrm{w}$ HAp.

This study has several intrinsic limitations due to the simplicity of the in vivo model. While it allowed for rapid screening at low costs for the number of independent samples tested, the resultant bone nodules were small and irregular and poorly suitable outcomes such as mechanical testing. Future studies looking at non-union or critical defect healing would be more suitable for examining mechanical parameters. They would also be able to evaluate an implant's applicability for bone repair as opposed to new ectopic bone formation. Nevertheless, these data have demonstrated in principle the efficacy of co-delivering rhBMP-2, low dose ZA, and HAp via a porous PLGA polymer scaffold in a pre-clinical model. These data represent a significant advancement in polymer based implant design for bone tissue engineering.

\section{Conclusion}

We have previously reported that low doses of local bisphosphonates can augment bone formation in a tissue-engineering model. In this study, we describe the development and testing of porous PLGAs loaded with a combination of rhBMP-2 and ZA-adsorbed HAp microparticles led to a maximal bone formation response. These studies demonstrate how scaffold design, anabolic and anti-catabolic drug doses, and the interactions between the two can be sequentially optimised to produce a highly effective implant. Future up-scaled experiments in more sophisticated orthopaedic models will be required to facilitate the clinical translation of this multifactorial approach.

\section{Acknowledgements}

Nicole Y. C. Yu was supported by the Australian National Health \& Medical Research Council (NHMRC) Biomedical Postgraduate Research Scholarship. Dr Schindeler receives salary support from NHMRC Project Grant APP1003478. This work was supported by NHMRC Project Grant APP1020987 and in part by ARC Discovery Grant DP110104446.

\section{References}

Athanasiou KA, Niederauer GG, Agrawal CM (1996) Sterilization, toxicity, biocompatibility and clinical applications of polylactic acid/ polyglycolic acid copolymers. Biomaterials 17: 93-102.

Belfrage O, Flivik G, Sundberg M, Kesteris U, Tägil M (2011) Local treatment of cancellous bone grafts with BMP-7 and zoledronate increases both the bone formation rate and bone density. Acta Orthopaedica 82: 228-233.

Bouxsein M, Blake C, Luppen C, Cooper J, Wozney J, Seeherman H (2001) Interaction between systemic bisphosphonate therapy and bone formation induced by local delivery of rhBMP-2 in non-human primates. J Bone Miner Res 16: S234.

Bouxsein ML, Boyd SK, Christiansen BA, Guldberg RE, Jepsen KJ, Müller R (2010) Guidelines for assessment of bone microstructure in rodents using micro-computed tomography. J J Bone Miner Res 25: 1468-1486.

Calandrelli L, Immirzi B, Malinconico M, Volpe MG, Oliva A, Della Ragione F (2000) Preparation and characterisation of composites based on biodegradable polymers for in vivo application. Polymer 41: 8027.

Calandrelli L, Immirzi B, Malinconico M, Luessenheide S, Passaro I, Pasquale R, Oliva A (2004) Natural and synthetic hydroxyapatite filled PCL: mechanical properties and biocompatibility analysis. J Bioact Compat Polym 19: 301-313.

Cao Y, Croll TI, Cooper-White JJ, O'Connor AJ, Stevens GW (2004) Production and surface modification of polylactide-based polymeric scaffolds for soft tissue engineering. In: Biopolymer methods in tissue engineering (Hollander AP, Hatton PV, eds), Humana Press, Totowa, NJ, pp 87-111.

Cao Y, Croll TI, O'Connor AJ, Stevens GW, CooperWhite JJ (2006a) Systematic selection of solvents for the fabrication of 3D combined macro- and microporous polymeric scaffolds for soft tissue engineering. J Biomater Sci Polymer Ed 17: 369-402.

Cao Y, Mitchell G, Messina A, Price L, Thompson E, Penington A, Morrison W, O'Connor A, Stevens G, Cooper-White J (2006b) The influence of architecture on degradation and tissue ingrowth into three-dimensional poly(lactic-co-glycolic acid) scaffolds in vitro and in vivo. Biomaterials 27: 2854-2864.

Causa F, Netti P, Ambrosio L, Ciapetti G, Baldini N, Pagani S, Martini D, Giunti A (2006) Poly-e-caprolactone/ hydroxyapatite composites for bone regeneration: In vitro characterization and human osteoblast response. J Biomed Mater Res 76A: 151-162. 
Chen W-J, Jingushi S, Hirata G, Matsumoto Y, Iwamoto Y (2004) Intramuscular bone inducation by the simultaneous administration of recombinant human bone morphogenetic protein 2 and bisphosphonate for autobone graft. Tissue Eng 10: 1652-1661.

Chen W-J, Jingushi S, Jingushi K, Iwamoto Y (2006) In vivo banking for vascularized autograft bone by intramuscular inoculation of recombinant human bone morphogenetic protein-2 and $\beta$-tricalcium phosphate. J Orthop Sci 11: 283-288.

Choi J-Y, Kim H-J, Lee Y-C, Cho B-O, Seong H-S, Cho M, Kim S-G (2007) Inhibition of bone healing by pamidronate in calvarial bony defects. Oral Surg Oral Med Oral Pathol Oral Radiol Endod 103: 321-328.

Coathup MJ, Blunn GW, Flynn N, Williams C, Thomas NP (2001) A comparison of bone remodelling around hydroxyapatite-coated, porous-coated and grit-blasted hip replacements retrieved at post-mortem. J Bone Joint Surg Br 83-B: 118-123.

DeLustro F, Dasch J, Keefe J, Ellingsworth L (1990) Immune responses to allogeneic and xenogeneic implants of collagen and collagen derivatives. Clin Orthop Relat Res 260: 263-279.

Geesink RGT, Hoefnagels NHM, Bulstra SK (1999) Osteogenic activity of OP-1 bone morphogenetic protein (BMP-7) in a human fibular defect. J Bone Joint Surg Br 81-B: 710-718.

Giannoudis PV, Einhorn TA, Marsh D (2007) Fracture healing: The diamond concept. Injury 38: S3.

Gong L, Hoshi K, Ejiri S, Nakajima T, Shingaki S, Ozawa H (2003) Bisphosphonate incadronate inhibits maturation of ectopic bone induced by recombinant human bone morphogenetic protein 2. J Bone Mineral Metab 21: 5-11.

Guillemin G, Meunier A, Dallant P, Christel P, Pouliquen JC, Sedel L (1989) Comparison of coral resorption and bone apposition with two natural corals of different porosities. J Biomed Mater Res 23: 765-779.

Harding AK, Aspenberg P, Kataoka M, Bylski D, Tägil M (2008) Manipulating the anabolic and catabolic response in bone graft remodeling: Synergism by a combination of local BMP-7 and a single systemic dosis of zoledronate. J Orthop Res 26: 1245-1249.

Hollister SJ (2005) Porous scaffold design for tissue engineering. Nat Mater 4: 518-524.

Idris A, Rojas J, Greig I, Van’t Hof R, Ralston S (2008) Aminobisphosphonates cause osteoblast apoptosis and inhibit bone nodule formation in vitro. Calcif Tissue Int. 82: 191-201.

Itoh K, Udagawa N, Katagiri T, Iemura S, Ueno N, Yasuda H, Higashio K, Quinn JMW, Gillespie MT, Martin TJ, Suda T, Takahashi N (2001) Bone morphogenetic protein 2 stimulates osteoclast differentiation and survival supported by receptor activator of nuclear factor-kB Ligand. Endocrinology 142: 3656-3662.

Jack KS, Velayudhan S, Luckman P, Trau M, Grøndahl L, Cooper-White J (2009) The fabrication and characterization of biodegradable HA/PHBV nanoparticlepolymer composite scaffolds. Acta Biomaterialia 5: 26572667.
Jakobsen T, Baas J, Bechtold JE, Elmengaard B, Soballe K (2007) Soaking morselized allograft in bisphosphonate can impair implant fixation. Clin Orthopaed Rel Res 463: 195-201.

Jakobsen T, Baas J, Bechtold J, Elmengaard B, Søballe K (2010) The effect of soaking allograft in bisphosphonate: A pilot dose-response study. Clin Orthopaed Rel Res 468: 867-874.

Jeppsson C, Åstrand J, Tägil M, Aspenberg P (2003) A combination of bisphosphonate and BMP additives in impacted bone allografts Acta Orthopaed Scand 74: 483489.

Jung Y, Kim S-S, Kim Y, Kim S-H, Kim B-S, Kim S, Choi C, Kim S (2005) A poly(lactic acid)/calcium metaphosphate composite for bone tissue engineering. Biomaterials 26: 6314-6322.

Kaneko H, Arakawa T, Mano H, Kaneda T, Ogasawara A, Nakagawa M, Toyama Y, Yabe Y, Kumegawa M, Hakeda Y (2000) Direct stimulation of osteoclastic bone resorption by bone morphogenetic protein (BMP)-2 and expression of BMP receptors in mature osteoclasts. Bone 27: 479.

Kato M, Toyoda H, Namikawa T, Hoshino M, Terai H, Miyamoto S, Takaoka K (2006) Optimized use of a biodegradable polymer as a carrier material for the local delivery of recombinant human bone morphogenetic protein-2 (rhBMP-2). Biomaterials 27: 2035.

Kim H-W, Knowles J, Kim H-E (2004) Effect of biphasic calcium phosphates on drug release and biological and mechanical properties of poly (epsilon-caprolactone) composite membranes. J Biomed Mater Res 70A: 467-479.

Little D, McDonald M, Bransford R, Godfrey C, Amanat N (2005) Manipulation of the anabolic and catabolic responses with OP-1 and zoledronic acid in a rat critical defect model. J Bone Miner Res 20: 2044-2052.

Little DG, Ramachandran M, Schindeler A (2007) The anabolic and catabolic responses in bone repair. $\mathrm{J}$ Bone Joint Surg Br 89-B: 425-433.

Liu X, Ma PX (2004) Polymeric scaffolds for bone tissue engineering. Ann Biomed Eng 32: 477-486.

Marx RE, Sawatari, Y., Fortin, M. \& Broumand, V. (2005) Bisphosphonate-induced exposed bone (osteonecrosis/osteopetrosis) of the jaws: Risk factors, recognition, prevention, and treatment. J Oral Maxillofac Surg 63: 1567-1575.

Middleton JC, Tipton AJ (2000) Synthetic biodegradable polymers as orthopedic devices. Biomaterials 21: 23352346.

Mikos AG, Thorsen AJ, Czerwonka LA, Bao Y, Langer R, Winslow DN, Vacanti JP (1994) Preparation and characterization of poly(l-lactic acid) foams. Polymer 35: 1068-1077.

Mönkkönen J, Similä J, Rogers MJ (1998) Effects of tiludronate and ibandronate on the secretion of proinflammatory cytokines and nitric oxide from macrophages in vitro. Life Sci 62: 95-102.

Mooney DJ, Kaufmann PM, Sano K, McNamara KM, Vacanti JP, Langer R (1994) Transplantation of hepatocytes using porous, biodegradable sponges. Transplant Proc 26: $3425-3426$. 
Olsen D, Yang C, Bodo M, Chang R, Leigh S, Baez J, Carmichael D, Perälä M, Hämäläinen E, Jarvinen M, Polarek J (2003) Recombinant collagen and gelatin for drug delivery. Adv Drug Deliv Rev 55: 1547-1567.

Pradhan B, Bae H, Dawson E, Patel V, Delamarter R (2006) Graft resorption with the use of bone morphogenetic protein: lessons from anterior lumbar interbody fusion using femoral ring allografts and recombinant human bone morphogenetic protein-2. Spine (Phila Pa 1976) 31: E377-384.

Rezwan K, Chen QZ, Blaker JJ, Boccaccini AR (2006) Biodegradable and bioactive porous polymer/ inorganic composite scaffolds for bone tissue engineering. Biomaterials 27: 3413-3431.

Rizzi S, Heath D, Coombes A, Bock N, Textor M, Downes S (2001) Biodegradable polymer/hydroxyapatite composites: Surface analysis and initial attachment of human osteoblasts. J Biomed Mater Res 55: 475-486.

Ruys AJ, Sorrell CC, Brandwood A, Milthorpe BK (1995) Hydroxyapatite sintering characteristics: correlation with powder morphology bv high-resolution microscopy. J Mater Sci Lett 14: 744-747.

Seeherman H, Li J, Blake C, Gavin D, Wozney J, Bouxsein M (2001) Histology indicates bisphosphonate limits transient resorption without decreasing bone induction in nonhuman primate core defects treated with rhBMP-2/ACS J Bone Miner Res 16: S438.

Seshima H, Yoshinari M, Takemoto S, Hattori M, Kawada E, Inoue T, Oda Y (2006) Control of bisphosphonate release using hydroxyapatite granules. J Biomed Mater Res B: Appl Biomater 78B: 215-221.

Shi X, Wang Y, Ren L, Gong Y, Wang D-A (2009) Enhancing alendronate release from a novel PLGA/ Hydroxyapatite microspheric system for bone repairing applications. Pharm Res 26: 422-430.

Smith EJ, McEvoy A, Little DG, Baldock PA, Eisman JA, Gardiner EM (2004) Transient retention of endochondral cartilaginous matrix with bisphosphonate treatment in a long-term rabbit model of distraction osteogenesis. J Bone Miner Res 19: 1698-1705.

Tägil M, Aspenberg P, Åstrand J (2006) Systemic zoledronate precoating of a bone graft reduces bone resorption during remodeling. Acta Orthop 77: 23-26.

Thiébaud D, Sauty A, Burckhardt P, Leuenberger P, Sitzler L, Green JR, Kandra A, Zieschang J, Ibarra de Palacios P (1997) An in vitro and in vivo study of cytokines in the acute-phase response associated with bisphosphonates. Calcif Tissue Int 61: 386-392.

Wei G, Ma PX (2004) Structure and properties of nano-hydroxyapatite/polymer composite scaffolds for bone tissue engineering. Biomaterials 25: 4749-4757.

Wolff J (1892) Das Gesetz der Transformation der Knochen (The Law of Bone Transformation) (English translation published by Springer-Verlag, Berlin, in 1986).

Yu H, Wooley P, Yang S-Y (2009) Biocompatibility of Poly-epsilon-caprolactone-hydroxyapatite composite on mouse bone marrow-derived osteoblasts and endothelial cells. J Orthopaed Surg Res 4: 5.

Yu NYC, Schindeler A, Little DG, Ruys AJ (2010a) Biodegradable poly( $\alpha$-hydroxy acid) polymer scaffolds for bone tissue engineering. J BiomedMater Res B: Appl Biomater 93B: 285-295.

Yu NYC, Schindeler A, Peacock L, Mikulec K, Baldock PA, Ruys AJ, Little DG (2010b) In vivo local co-delivery of recombinant human bone morphogenetic protein-7 and pamidronate via poly-D, L-lactic acid. Eur Cell Mater 20: 431-442.

Yu NYC, Schindeler A, Tägil M, Ruys A, Little D (2012) Use of BMPs and bisphosphonates in improving bone fracture healing. Front Biosci (Elite Ed) 4: 2647-2653.

\section{Discussion with Reviewers}

J. Gasser: Ideally, mechanical properties of the PLGA and PDLLA discs should be assessed. Please also discuss how the differences in material, porosity, degradation rate and other factors could have influenced the results.

Authors: Additional control groups examining BMP + HAp (without ZA) were not tested for several reasons. Firstly, post-hoc addition of extra groups would not have been scientifically valid, as the gold standard for orthopaedic studies is to perform all surgeries at the same time under identical conditions. Secondly, these were not part of our original hypothesis that HAp could bind and enhance the effects of ZA; understanding the capacity of HAp to affect bone in the absence of ZA is a separate research question that we believe merits its own focused study.

Reviewer II: Do you think that addition of a bisphosphonate could lower the required BMP dose in current clinical settings, and thereby reduce the important adverse effects of BMP-2, which were recently highlighted by Carragee et al. (2011) (additional reference).

Authors: Our data would suggest that this is the case, although to date the majority of preclinical studies (such as those cited in the introduction and discussion) have concentrated on using equivalent rhBMP doses and showing increases in bone with bisphosphonates. Notably, using an optimised delivery system can yield equal bone volume for a lesser rhBMP-2 dose ( $5 \mu \mathrm{g}$ rhBMP-2 in porous PLGA $=20 \mu \mathrm{g}$ rhBMP-2 in solvent cast PDLLA). However, we recognise a need to be conservative when drawing conclusions from preclinical models and further testing is required to validate this in a clinical setting. Still, a capacity to use reduced rhBMP-2 doses by bisphosphonate addition while avoiding potential adverse events gives further justification for pursuing this line of research.

Reviewer II: Heterotopic bone formation is a regularly seen negative side-effect of the use of supraphysiological concentrations of BMP-2 in clinical situation. Based on the results of this study, would you expect addition of bisphosphonates to the implants containing BMP-2 to affect incidence of heterotopic bone formation around the defect area and if so, in which way?

Authors: The addition of bisphosphonates to the implants containing BMP-2 is not expected to affect the incidence of heterotopic bone formation around the defect area. Based 
on this heterotopic bone formation study, local release of BMP-2 + bisphosphonate (via hydroxyapatite ceramic particles at $2 \% \mathrm{w} / \mathrm{w}$ ) did not result in a significant increase in ectopic bone formation, compared to BMP-2 alone. The representative 3-dimensional microCT representative images showed bone in-growth into the scaffold instead of bone formation spreading away from the scaffold space.

Reviewer III: You suggest that future studies should be performed in large animals in models of critical defect healing. Could you please comment on the exact model to be used, and what your expectations are regarding the outcome, taking into account differences in species, orthotopic environment, loading, etc.?

Authors: Our current future plans involve a two stage process of preclinical testing. Based on positive results in an ectopic bone formation model (described in this paper), we next plan to test the implant design in an established rat critical-sized defect model (Little et al., 2005 , text reference). This model features a $6 \mathrm{~mm}$ criticalsized full-thickness with periosteal stripping and internal plated fixation. We expect that ZA/HAp co-treatment will perform better than BMP alone. This model will be a better reflection of the type of orthopaedic injury that the implant is designed to treat.

\section{Additional Reference}

Carragee EJ, Hurwitz EL, Weiner BK (2011) A critical review of recombinant human bone morphogenetic protein-2 trials in spinal surgery: emerging safety concerns and lessons learned. Spine J 11: 471-491. 